\title{
Youdale, Roy. Using computers in the translation of literary style. Nova Iorque: Routledge, 2020, $242 \mathrm{p}$.
}

Emily Arcego 1

Fernanda Saraiva Frio 1

1-Universidade Federal de Santa Catarina, Florianópolis, Santa Catarina, Brasil

O livro Using Computers in the Translation of Literary Style, de Roy Youdale, professor da Bristol University, apresenta uma proposta de aliar o uso de tecnologia, através dos softwares de análise linguística e das CAT Tools, à tradução do texto literário. Conforme o autor, o recurso ao computador fornece dados que mesmo uma leitura atenta não seria capaz de detectar, consequentemente, o tradutor pode tomar decisões mais bem informadas na hora de traduzir uma obra de literatura.

A obra é dividia em oito capítulos mais a introdução; esta se dedica a descrever termos-chave que serão importantes para a discussão proposta nos capítulos seguintes. O primeiro deles é o conceito de estilo, que Youdale (2020) concebe a partir de uma perspectiva comunicativa - o foco recai não apenas sobre $o$ que se diz mas também sobre como se diz - e distintiva - quais características linguísticas singulares na escrita de determinado texto podem causar um efeito perceptível no leitor.

Outros dois conceitos fundamentais trazidos à tona são os de leitura atenta (close reading) e leitura distante (distant reading). A leitura atenta, como o próprio nome sugere, consiste em ler um texto ou 
parte dele cuidadosamente, fazendo observações no nível microtextual, para encontrar pistas que ajudem a compreender o todo; já a leitura distante envolve a análise do texto assistida por computador, que possibilita rearranjar o texto de diversas formas, para detectar aspectos que escapam à leitura atenta. É a partir dessas duas abordagens que Youdale (2020) vai descrever, ao longo de seu livro, as estratégias que usou em sua tradução de Gracias por El Fuego, romance do escritor uruguaio Mario Benedetti.

O primeiro capítulo, "Using Computers in Literary Translation", apresenta um panorama dos primeiros passos dados pela tradução assistida por computador. É feito um balanço entre os impactos positivos e negativos que a tecnologia exerce sobre a prática tradutória. Dentro os pontos negativos, está a possível mecanização do trabalho, que pode afetar não somente os ganhos do tradutor como também sua própria capacidade, uma vez que a máquina se torna responsável por parte da tarefa. Por outro lado, essas tecnologias podem aumentar a produtividade, conferir consistência à tradução e agilizar tarefas maçantes e repetitivas.

O autor também refuta a ideia preconcebida de que as memórias de tradução são mais adequadas para textos acadêmicos e jurídicos, em vez de textos literários. Ele afirma que muitos textos literários, incluindo o livro de Benedetti que ele se propôs a traduzir, têm linguagem simples e objetiva, ao passo que textos médicos e legais, por exemplo, muitas vezes apresentam maior variação lexical e estruturas mais complexas.

Também neste capítulo nos são apresentadas algumas ferramentas, disponíveis em diversos softwares de análise linguística, que podem auxiliar o tradutor em sua análise do texto a ser traduzido e a observar problemas na sua própria tradução. O autor lembra que, para isso, é fundamental o recurso aos métodos oferecidos pela linguística de corpus, que incluem fazer listas de palavras ou frases mais frequentes em um texto, listas de concordância - que 
elencam uma mesma palavra nos diversos contextos em que ela aparece no corpus -, estabelecer critérios de busca complexos que ficam "invisíveis" em uma leitura corriqueira - como variedade lexical, classes gramaticais predominantes no texto, tamanho médio de frases e períodos.

No capítulo 2, Youdale (2020) elenca os primeiros passos dados para sua tradução romance "Gracias por el Fuego", sendo o primeiro deles uma pesquisa abrangente sobre o autor, suas obras e sua recepção. É proposto um modelo em 4 passos para realizar a tradução aliando leitura atenta e distante. O primeiro deles consiste em fazer uma leitura inicial do texto, sem auxílio de computador, e tomar notas sobre os aspectos narrativos, lexicais, gramaticais e contextuais e coesivos do texto. Os aspectos narrativos incluem informações sobre a estrutura da narrativa, as personagens, a descrição de tempo e espaço; a análise lexical envolve o uso de discursos específicos, palavras e colocações incomuns, expressões idiomáticas e referentes culturais; no domínio gramatical devem ser identificadas os tipos de orações, períodos, suas extensões e o uso de pontuação; por fim, os aspectos contextuais e coesivos abrangem questões como o tamanho dos parágrafos, a repetição de palavras e frases, a prosódia semântica, uso de recursos coesivos e escolhas tipográficas.

Youdale (2020) também apresenta as ferramentas de análise linguística que podem ser úteis ao tradutor após essa leitura inicial. A primeira delas são os chamados corpus summaries, que possibilitam realizar a contagem de palavras e organizá-las em uma lista de frequência, estabelecer a razão tokens/types ${ }^{l}$, elencar as palavras usadas com mais frequência e estimar o tamanho médio das frases, o que possibilita identificar o nível de complexidade e riqueza gramatical do texto. Além disso, uma ideia do grau de riqueza lexical do texto-fonte constitui uma referência para avaliar

${ }^{1} \mathrm{O}$ número de tokens e types indica, respectivamente, o número total de palavras presentes no texto e o número de vocábulos distintos que foram utilizados.

Cad. Trad., Florianópolis, v. 41, no 2 p. 438-446, mai-ago, 2021. 
o primeiro rascunho da tradução. As word lists são um recurso que podem oferecer ao tradutor pistas temáticas e confirmar ou refutar impressões geradas pela leitura inicial, além de ajudar a determinar as palavras-chave do texto, isto é, palavras que são mais ou menos frequentes em comparação a um corpus de referência. Outro mecanismo relevante para a tradução são os n-grams, que mostram sequências repetidas de palavras, ajudando a revelar padrões linguísticos e determinar se eles são estilisticamente relevantes. Esses recursos são explorados ao longo dos capítulos seguintes, que trazem uma descrição mais detalhada da tradução de Gracias por el Fuego realizada por Youdale (2020).

O capítulo 3 traz a fundamentação teórica que sustenta o projeto de tradução do autor, qual seja, o de realizar uma tradução primordialmente estrangeirizadora, criando, assim, um "Benedetti inglês". Ele também discute o conceito de invisibilidade do tradutor, contra o qual quer lutar em seu trabalho. Para o autor, o objetivo de sua tradução, e que deveria ser o objetivo de outras, é justamente proporcionar ao leitor o contato com a cultura estrangeira, e não fazer de modo que o texto "engane" o leitor ao "soar" como escrito originalmente na cultura de chegada. Outra premissa questionada pelo autor é de que a tradução deve gerar, no seu leitor, o mesmo efeito - conceito que nunca foi bem definido - que o texto de partida exerceu sob o público de origem, o que, paradoxalmente, se costuma exigir de um tradutor. Essa ideia é problemática na medida em que não define o que é efeito e porque exige que este seja preservado, mesmo quando se lida com uma cultura e uma época diferente. Youdale (2020) afirma que, em sua empreitada, buscou recriar para os leitores da tradução os mesmos efeitos que o texto exerceu nele, que é a única medida sobre a qual ele possuía algum domínio. $\mathrm{O}$ autor cita como exemplo as frases longas e repetitivas presentes no texto de Benedetti e que, conforme análise em corpora de referência, constituem uma estrutura marcada em espanhol e um traço distintivo da escrita do autor uruguaio, que Youdale (2020) buscou preservar na tradução. 
O capítulo 4 se dedica à tradução de itens culturais (culture-specific items, conforme terminologia proposta por Aixelá, 1996), presença de outras línguas estrangeiras no texto e o registro formal, representado pelo uso de usted. Quanto aos itens culturais, Youdale (2020) sugere que eles não devem ser traduzidos caso a caso, procurando soluções individuais, e sim analisados em sua função, nos níveis micro e macrotextuais. Ele cita o exemplo da palavra falluto, associada ao espanhol rio-platense, cujo significado vai desde hipócrita até traiçoeiro. O termo é usado seis vezes ao longo da história e, de acordo com Youdale (2020), é importante porque está diretamente ligado ao tema da hipocrisia moral e política, que é central no livro. Em vez de procurar um termo correspondente em inglês, a solução do tradutor foi preservar a palavra em espanhol e incluí-la em um glossário, que ficaria no final do livro, o que converge com seu projeto de apresentar uma tradução estrangeirizadora. Quanto às outras línguas estrangeiras que aparecem no texto de partida - inglês, francês, alemão e latim -, elas foram, aparte o inglês, preservadas no texto. Para lidar com trechos em inglês, idioma para o qual o livro foi traduzido, o autor recorreu à tipografia para que essas partes ganhassem destaque no texto - é o caso, por exemplo, de trechos em que um personagem conversa com seus clientes norte-americanos, que falam, obviamente, inglês, portanto, converter essas falas para espanhol não faria sentido. No caso de excertos que misturavam os dois idiomas, inglês e espanhol, a solução foi inverter as línguas na tradução e recorrer, igualmente, ao destaque tipográfico dos excertos em inglês. Em relação ao uso de usted, Youdale (2020) recorreu a corpora de referência para observar como outros tradutores lidavam com esse pronome; na maioria dos casos, usted era normalizado e transformado em you, apagando a dimensão de registro formal do texto. A solução para preservar a formalidade e criar um texto estrangeirizador foi traduzir usted como you e acrescentar, ao final da frase, o vocativo Señor ou Señora.

No capítulo 5, o autor se dedica a analisar os padrões de pontuação do texto de partida para que sua tradução atente a esses aspectos, que 
são, muitas vezes, ignorados ou alterados em traduções de textos literários. Youdale (2020) afirma que, ainda que o tamanho das sentenças seja uma característica facilmente percebida pelo leitor, é a análise assistida por computador que vai ajudar na quantificação e análise desses dados. Em seu trabalho, o autor observou que boa parte das sentenças em Gracias por el Fuego eram curtas - 65\% delas continham 10 palavras ou menos -, predominando ao longo do texto - o tamanho médio das sentenças no livro inteiro era de 11,5 palavras. Por outro lado, a análise quantitativa também revelou a presença de 30 sentenças $(0,5 \%$ do total) longas, contendo de 101 a 713 palavras. $\mathrm{O}$ autor analisa esses dados à luz de corpora de referência de outros textos ficcionais escritos em língua espanhola, que revela que o tamanho médio das sentenças desses textos era de 17,5 palavras, portanto, Gracias por el Fuego revela um padrão de uso de sentenças curtas. $\mathrm{O}$ desafio do tradutor, foi lidar com excertos como Hacia abajo es desprecio. Hacia arriba, admiración, frases extremamente curtas, em que não há sujeito e, no caso do exemplo, o número de sílabas em cada frase é idêntico ( 9 em cada uma). A solução encontrada foi usar Superiors despise. Inferiors demise, com número ainda menor de palavras e preservando a estrutura com mesmo número de sílabas.

O capítulo 6 descreve como o autor, após concluir seu primeiro rascunho da tradução, estabelece uma comparação entre o texto de partida e o texto de chegada, que é feita através das ferramentas citadas no capítulo 2, além de aplicar análise estatística, sobre a qual não entra em muitos detalhes, apenas apresenta os resultados encontrados ao leitor. O primeiro critério de comparação é a diversidade lexical e o uso da pontuação em cada um dos textos, quantificada através das word lists, da razão tokens/types, da identificação de palavras que aparecem somente uma vez no texto - as chamadas hápax legómenon - e do tamanho médio e número de sentenças. A primeira conclusão geral da análise mostra que o número de palavras e sentenças, no geral, foi observado na tradução, a segunda mostra que a tradução apresenta densidade lexical menor, no entanto, um exame mais atento mostrou que essa diferença se deu, primeiramente, pela 
natureza inflexiva da língua espanhola, o que aumentaria o número de types na contagem, além do fato de que alguns verbos em inglês, como to know e to be, podem ser expressos de forma diferente em espanhol, como saber/conocer e ser/estar, respectivamente. $\mathrm{Na}$ comparação entre as sentenças do texto fonte e da tradução, Youdale (2020) observou que, em seu texto, a proporção de sentenças de 1-10 palavras e de 101 palavras foi preservada, mas houve uma redução no número de excertos de 1-6 palavras, que foram analisadas caso a caso e cuja explicação reside, na maior parte das instâncias, na diferença entre os dois idiomas trabalhados. Para que a comparação não se baseasse somente em números, os dois textos também foram alinhados para ajudar a identificar as razões pelas quais havia algumas discrepâncias. Neste ponto, é inevitável se perguntar por que Youdale (2020) não usou, em seu primeiro rascunho da tradução, uma CAT Tool, que, além de ajudar a identificar trechos iguais ou semelhantes no texto de partida, deixa-o alinhado com sua tradução. Infelizmente, o autor não oferece respostas a essa pergunta, assim como não descreve de que forma realizou sua tradução, discorrendo apenas sobre a análise preliminar do texto e sobre a posterior comparação entre Gracias por el Fuego e sua tradução para o inglês.

No capítulo 7, último antes da conclusão, Youdale (2020) se propõe a comparar duas traduções suas, do espanhol para o inglês, com seus respectivos textos-fonte e com uma tradução de um mesmo texto feita por um terceiro, para fazer uma análise de seu estilo como tradutor, isto é, os padrões linguísticos que tornam sua escrita distintiva. Os textos escolhidos foram a tradução de El Discurso Vacío, do escritor uruguaio Mario Levrero, feita sem o auxílio de ferramentas de análise linguística, e de Gracias por el Fuego, mais especificamente, o capítulo 13, que, de acordo com Youdale (2020), é representativo do texto, similar em tamanho ao texto de Levrero e dotado de características temáticas e linguísticas distintivas. A investigação consistiu em estabelecer comparações entre os textos-fonte e as duas traduções realizadas por Youdale (2020) e entre sua tradução de El Discurso Vacío e aquela que foi feita 
por um terceiro, para verificar quais escolhas tradutórias foram motivadas por preferências estilísticas. Essa análise chegou a sete padrões linguísticos que o autor afirma usar de forma inconsciente, quais sejam: alteração do tempo verbal em frases que estavam no tempo verbal presente; a conversão de particípio passado e gerúndio em infinitivo; a mudança de voz ativa para voz passiva; a substituição de travessão por vírgula; aumento no grau de ênfase em comparação com o texto de partida; simplificação. Por questões de espaço, não podemos, como fez o autor, nos deter sobre cada um desses traços estilísticos, mas, usando novamente corpora de referência, Youdale (2020) conclui que essas mudanças, ainda que parte delas seja motivada por diferenças gramaticais, são distintivas de seu modo de escrever e, portanto, refletem seu estilo como tradutor. Isso é relevante não apenas para o tradutor refletir sobre sua prática, mas também conferir consistência às decisões tradutórias, que passam a ser tomadas de forma mais consciente.

Por fim, o capítulo 8 traz um apanhado de tudo que foi visto ao longo do livro e tece as considerações finais. Aqui, tomamos a liberdade de apresentar nossas próprias conclusões sobre a relevância da obra. Não há dúvida que a tradução literária pode se beneficiar do recurso ao computador e às ferramentas de análise linguística. Há, porém, dois contrapontos: o primeiro diz respeito à proficiência do tradutor no uso desses tipos software; além de variados, nem todos possuem uma interface intuitiva, o que implica que seu uso eficiente exige tempo para que o tradutor se habitue aos programas e aprenda a tirar proveito de todos os recursos que eles oferecem. Em segundo lugar, a análise linguística sem uma leitura crítica dos dados pouco pode fazer pela tradução; dados estatísticos, gráficos, tabelas etc. nada dizem ao tradutor que não consegue interpretá-los. Esses dois aspectos, além de demandar tempo para seu aprendizado, muitas vezes requerem investimento financeiro, uma vez que alguns softwares só são disponibilizados em suas versões de teste, que são muito limitadas em comparação às versões pagas. 
Dito isso, concluímos esta resenha com uma avaliação positiva da obra Using Computers in the Translation of Literary Style, que, já em sua introdução, se compromete a oferecer definições de todos os conceitos explorados ao longo do livro, sempre respaldadas por outros trabalhos realizados no âmbito dos Estudos da Tradução. Para cada etapa de análise ou método apresentado, são também mencionados exemplos e imagens que ajudam o leitor a ter um melhor entendimento de como esses procedimentos são realizados. Em cada capítulo, é feita uma análise minuciosa de cada dado revelado pelos programas de computador, mostrando que, de fato, o auxílio do computador é capaz de trazer à tona características que escapam a uma leitura, mesmo que atenta. O trabalho de Youdale (2020) é original e inovador, e os tradutores de textos literários, professores e estudantes de tradução e demais interessados pelo tema só têm a ganhar com a leitura dessa obra.

\section{Referências}

Aixelá, J. "Culture-specific items in translation". Translation, Power, Subversion, Álvarez, R.; Vidal, C (Eds.). Clevedon: Multilingual Matters, 1996.

Benedetti, M. Gracias por el Fuego. Madri: Alianza Editorial, 2014.

Recebido em: 05/01/2021

Aceito em: 02/04/2021

Publicado em maio de 2021

Emily Arcego. E-mail: arcegoemily@gmail.com. ORCID: https://orcid. org/0000-0002-6215-3980.

Fernanda Saraiva Frio. E-mail: fernandasfrio@gmail.com. ORCID: https://orcid. org/0000-0002-3290-646X. 